\title{
Faktor Pemilihan Lokasi Apartemen Berdasarkan Preferensi Pemerintah di Surabaya Metropolitan Area
}

\author{
Erisa Nur Agmelina dan Putu Gde Ariastita \\ Departemen Perencanaan Wilayah dan Kota, Fakultas Teknik Sipil dan Perencanaan, Institut \\ Teknologi Sepuluh Nopember (ITS) \\ e-mail: ariastita@urplan.its.ac.id
}

\begin{abstract}
Abstrak-Pembangunan apartemen di Surabaya Metropolitan Area merupakan salah satu upaya yang dilakukan pemerintah untuk memenuhi kebutuhan perumahan. Secara harfiah apartemen yang mendukung konsep urban compactness mayoritas dibangun di pusat perkotaan. Namun, perkembangan apartemen saat ini cenderung menyebar. Berdasarkan penelitian terdahulu pengembang belum memperhatikan preferensi penghuni dalam pembangunan apartemen sehingga apartemen terbangun bebas mengikuti lahan yang dimiliki oleh pengembang. Selain itu, pemerintah belum memiliki regulasi spesifik mengenai pengaturan lokasi apartemen namun pemerintah tetap memberikan peluang besar terhadap pembangunan apartemen. Hal tersebut menunjukkan bahwa belum ditemukan adanya faktor preferensi mengenai penentuan lokasi apartemen yang sama-sama disetujui oleh ketiga stakeholders yaitu pemerintah, pengembang, dan masyarakat. Oleh karena itu, tujuan dari penelitian ini adalah untuk merumuskan faktor prioritas dalam menentukan lokasi pembangunan apartemen di Surabaya Metropolitan Area berdasarkan preferensi pemerintah. Penelitian ini menggunakan dua teknik analisis yaitu Analytic Network Process dan analisis deskriptif. Hasil dari penelitian ini adalah faktor pemilihan lokasi apartemen yang disetujui oleh pemerintah yaitu jarak ke jalan utama, kesesuaian dengan RTRW, harga lahan, dan jarak ke pusat pelayanan kota.
\end{abstract}

Kata Kunci-Analytical Network Process, Apartemen, Pemilihan Lokasi.

\section{PENDAHULUAN}

$\mathrm{F}$ ENOMENA pertumbuhan gedung-gedung tinggi yaitu apartemen meningkat di Kota Surabaya selama 7 tahun terakhir. Pembangunan apartemen merupakan bentuk upaya yang dilakukan Pemerintah Kota Surabaya dalam memenuhi kebutuhan perumahan [1]. Dalam RTRW Kota Surabaya Tahun 2014-2034, Pemerintah Kota Surabaya telah memberikan peluang yang besar dalam pembangunan dan pengembangan apartemen. Hal ini terlihat dari banyaknya distribusi unit apartemen yang telah dibangun hingga tahun 2016 sebanyak 19.905 unit [2].

Menurut teori lokasi apartemen ditempatkan berada dekat dengan area "two-flat" atau area "working men's homes" yang tidak jauh dari central business district (CBD) dan bright-light area [3]. Namun, apartemen di Kota Surabaya tumbuh menyebar secara acak dan tidak berada dekat dengan sistem pusat pelayanan Kota Surabaya. Saat ini para investor menginginkan kawasan-kawasan pinggiran untuk berinvestasi [4]. Hal tersebut dapat dilihat dari banyaknya pengembang apartemen yang telah mengajukan pembangunan apartemen yang berada di wilayah barat, timur, dan selatan sebanyak 16.241 unit yang direncanakan beroperasi pada tahun 2019. Namun, saat ini semakin banyak unit apartemen yang tidak berpenghuni dikarenakan hanya berfungsi sebagai sarana investasi [5]. Hal tersebut menandakan bahwa fungsi apartemen tidak tepat guna jika ditinjau sebagai kawasan hunian. Selain itu, mengingat posisi Kota Surabaya sebagai Surabaya Metropolitan Area maka pertumbuhan apartemen ini mulai diikuti di wilayah sekitarnya yaitu Kabupaten Sidoarjo dan Kabupaten Gresik.

Pertumbuhan persebaran apartemen di Surabaya Metropolitan Area menyebabkan beberapa dampak yang timbul. Salah satu buktinya dapat dilihat dari penurunan kinerja jalan yang terjadi di Jalan Arif Rahman Hakim setelah tiga apartemen beroperasi di Surabaya Timur yaitu Apartemen Puncak Kertajaya, Cosmopolis Apartment, dan Apartemen Sukolilo Dian Regency [6]. Hal serupa juga terjadi pada keberadaan Apartemen De Papilio Tamansari di Surabaya Selatan yang telah menyebabkan terjadinya bangkitan perjalanan pada jalan di sekitar lokasi yang berdampak pada bertambahnya volume lalu lintas di sekitar lokasi [7]. Selain itu dampak buruk dari pembangunan apartemen di lokasi yang tidak tepat dapat membuat harga lahan di sekitarnya naik dan meningkatnya harga tanah secara signifikan.

Kemunculan apartemen di Surabaya Metropolitan Area ini ditujukan untuk masyarakat golongan menengah ke atas yang sedang membutuhkan hunian. Namun begitu, masyarakat yang merupakan calon penghuni dan penghuni memiliki perbedaan persepsi dalam memilih lokasi huniannya. Lokasi yang diinginkan salah satunya merupakan lokasi yang memudahkan penghuni untuk melakukan aktivitas seperti kedekatan dengan pusat kota, tempat kerja, jaringan jalan, dan jarak ke angkutan umum [8]. Hal ini menunjukkan bahwa pihak-pihak yang memegang peran dalam membangun, mengatur, dan memberikan ijin apartemen perlu memerhatikan permintaan masyarakatnya khususnya dalam pemilihan lokasi apartemen. Pada nyatanya developer dalam melakukan pembangunan apartemen kurang memerhatikan persepsi masyarakat dalam memilih lokasinya. Di samping itu pemerintah belum memiliki instrumen pengaturan lokasi apartemen sehingga pertumbuhan apartemen saat ini belum terarah. 
Permasalahan penyebaran lokasi apartemen tersebut mengindikasikan bahwa belum ada faktor pemilihan lokasi apartemen yang disepakati oleh pihak-pihak yang berkaitan dalam pembangunan apartemen. Developer masih belum memperhatikan preferensi masyarakat sebagai konsumen. Preferensi masyarakat menginginkan apartemen yang mudah dicapai, namun preferensi developer cenderung memilih lokasi apartemen yang dapat dijangkau oleh moda transportasi [9]. Dikarenakan banyaknya partisipasi dalam pembangunan apartemen seperti pemerintah, pengembang, masyarakat, dan sebagainya tidak dapat dipungkiri akan adanya perbedaan preferensi antara beberapa pihak. Penelitian ini ingin mengetahui faktor pemilihan lokasi apartemen berdasarkan preferensi pemerintah. Maka dari itu, tujuan dari penelitian ini merumuskan faktor-faktor prioritas dalam pemilihan lokasi apartemen berdasarkan preferensi pemerintah.

\section{METODE PENELITIAN}

\section{A. Variabel Penelitian}

Penelitian ini merupakan penelitian kuantitatif deskriptif dimana masih berorientasi pada data kuantitatif dimana menggunakan angka atau skala yang menjadi temuan utama dari sebuah penelitian. Sedangkan metode deskriptif digunakan untuk menjelaskan peristiwa suatu kejadian dalam bentuk angka-angka. Variabel penelitian didapatkan dari hasil sintesa tinjauan pustaka yang memiliki pengaruh dalam pemilihan lokasi apartemen dan gedung tinggi.

Tabel 1.

Indikator dan Variabel Penelitian

\begin{tabular}{|c|c|c|}
\hline No. & Indikator & Variabel \\
\hline 1 & Aksesibilitas & $\begin{array}{c}\text { Jarak ke pusat pelayanan kota } \\
\text { Transportasi umum } \\
\text { Jarak ke jalan utama }\end{array}$ \\
\hline 2 & Tata ruang & $\begin{array}{c}\text { Kesesuaian dengan RTRW } \\
\text { Harga lahan }\end{array}$ \\
\hline 3 & Fisik & $\begin{array}{c}\text { Topografi } \\
\text { Genangan pada lahan }\end{array}$ \\
\hline 4 & $\begin{array}{l}\text { Karakteristik } \\
\text { lingkungan }\end{array}$ & $\begin{array}{c}\text { Estetika } \\
\text { Tingkat Keamanan }\end{array}$ \\
\hline 5 & Mekanisme pasar & $\begin{array}{l}\text { Permintaan pasar } \\
\text { Proyeksi penduduk }\end{array}$ \\
\hline 6 & Sarana & $\begin{array}{c}\text { Kemampuan pengembang } \\
\text { Sarana kesehatan } \\
\text { Sarana pendidikan } \\
\text { Sarana rekreasi } \\
\text { RTH }\end{array}$ \\
\hline 7 & Prasarana & $\begin{array}{c}\text { Jaringan air bersih } \\
\text { Jaringan listrik } \\
\text { Jaringan telepon } \\
\text { Jaringan jalan } \\
\text { Drainase }\end{array}$ \\
\hline
\end{tabular}

\section{B. Metode Pengambilan Sampel}

Pengambilan sampel pada pihak pemerintah menggunakan teknik purposive sampling. Purposive sampling bertujuan agar sampel terpilih merupakan responden yang memahami wilayah dan objek penelitian. Pihak pemerintah yang terpilih menjadi responden adalah pihak yang memiliki peran dalam pemilihan lokasi apartemen dan mengetahui ketentuan perizinan lokasi pembangunan apartemen. Berikut merupakan responden pada penelitian ini:
Tabel 2.

Responden Penelitian

\begin{tabular}{|c|c|c|}
\hline No. & Responden & Kepentingan \\
\hline 1 & Bappeko Surabaya & \\
\hline 2 & Bappeda Kabupaten Sidoarjo & $\begin{array}{l}\text { Mengoptimalkan pemanfaatan } \\
\text { ruang kota dengan menyusun }\end{array}$ \\
\hline 3 & Bappeda Kabupaten Gresik & kebijakan penataan ruang \\
\hline 4 & $\begin{array}{l}\text { Dinas Perumahan Rakyat dan } \\
\text { Kawasan Permukiman, Cipta } \\
\text { Karya dan Tata Ruang Kota }\end{array}$ & \\
\hline 5 & $\begin{array}{l}\text { Surabaya } \\
\text { Dinas Perumahan dan }\end{array}$ & $\begin{array}{l}\text { Penyusunan kebijakan teknis di } \\
\text { bidang tata kota dan permukiman }\end{array}$ \\
\hline & $\begin{array}{l}\text { Permukiman } \\
\text { Sidoarjo }\end{array}$ & \\
\hline 6 & $\begin{array}{l}\text { Dinas Pekerjaan Umum Cipta } \\
\text { Karya dan Tata Ruang } \\
\text { Kabupaten Gresik }\end{array}$ & \\
\hline
\end{tabular}

Sampel di atas merupakan sampel representatif yang mewakili seluruh populasi dari wilayah penelitian ini. Wilayah studi pada penelitian adalah Kota Surabaya, sebagian Kabupaten Sidoarjo yaitu Kecamatan Waru dan Taman dan sebagian Kabupaten Gresik yaitu Kecamatan Kebomas dan Gresik. Wilayah pada penelitian ini dapat dilihat pada gambar berikut:

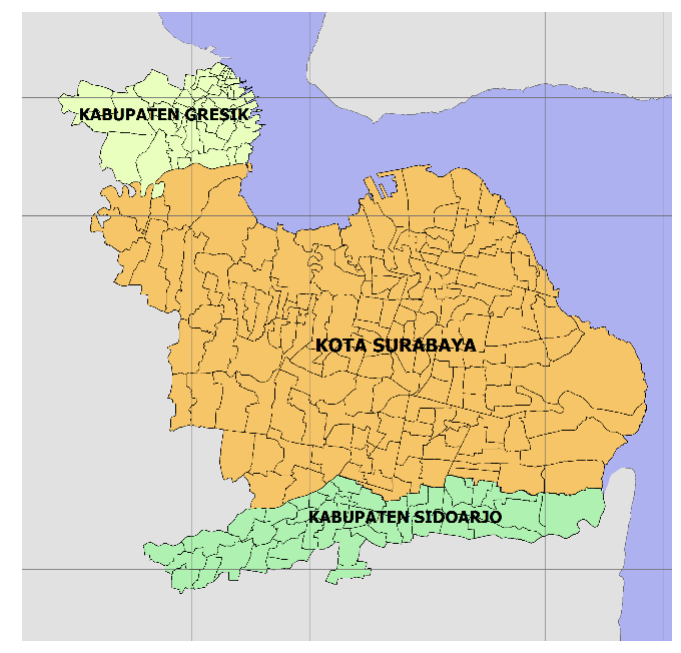

Gambar 1.Peta Wilayah Studi.

\section{Metode Pengumpulan Data}

Metode pengumpulan data yang digunakan dalam penelitian ini adalah teknik survei primer dan sekunder. Survei primer dilakukan melalui wawancara dengan menggunakan kuesioner kepada stakeholders terpilih yang terdiri dari instansi pemerintah (BAPPEDA Kota Surabaya, BAPPEDA Kabupaten Sidoarjo, BAPPEDA Kabupaten Gresik, Dinas Perumahan Rakyat dan Kawasan Permukiman CKTR Kota Surabaya, Dinas Perumahan dan Permukiman Kabupaten Sidoarjo, dan Dinas PU CKTR Kabupaten Gresik). Selain data primer, dilakukan pengumpulan data sekunder dengan studi literatur yang didapatkan melalui instansi-instansi terkait. 


\section{Metode Analisis}

Dalam penelitian ini terdapat tiga analisis yang akan dilakukan. Untuk merumuskan faktor pemilihan lokasi apartemen berdasarkan preferensi pemerintah digunakan alat analisis yaitu Analytic Network Process (ANP) untuk mengidentifikasi faktor yang diprioritaskan oleh responden melalui nilai bobot antar faktor pemilihan lokasi apartemen. Berikut ini merupakan ilustrasi dari jaringan ANP.

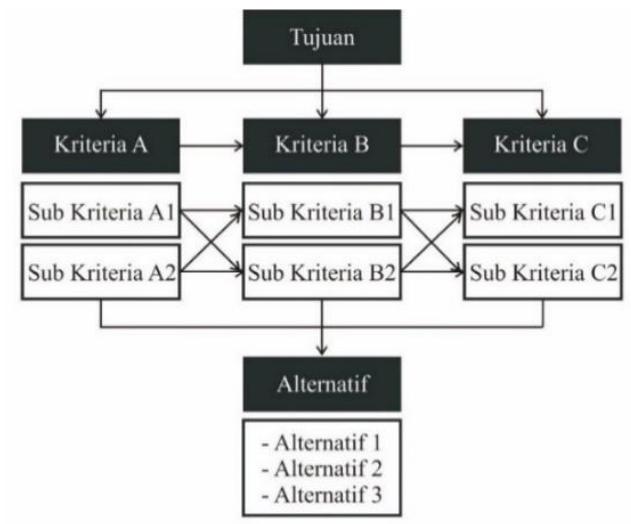

Gambar 2. Ilustrasi ANP.

\section{HASIL DAN PEMBAHASAN}

\section{A. Pembobotan Faktor dan Sub Faktor Prioritas Pemilihan Lokasi Apartemen Preferensi Pemerintah}

Untuk merumuskan faktor dan sub faktor prioritas pemilihan lokasi apartemen berdasarkan preferensi pemerintah dilakukan analisis Analytic Network Process (ANP). ANP merupakan suatu teknik analisis untuk pengambilan keputusan faktor-faktor yang saling berhubungan secara sistematik. Kelebihan yang dimiliki oleh metode ANP adalah dimungkinkannya pemodelan hubungan keterkaitan antar faktor dan sub faktor. ANP menggunakan jaringan atau network sehingga hubungan antar faktor lebih luas. Terdapat dua hubungan yaitu outer dependence dan inner dependence. Inner dependence adalah hubungan yang terjadi antar sub faktor di dalam faktor yang sama. Sedangkan outer dependence adalah hubungan yang terjadi antar sub faktor dalam faktor-faktor yang berbeda [10].

\begin{tabular}{|c|c|c|c|c|c|c|}
\hline Inconsistency & Fisik & Karakteris & Mekanisme & Prasarana & Sarana & 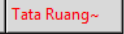 \\
\hline Aksesibili & $\leftarrow 3.95$ & $\leftarrow 3.95$ & $\leftarrow 1.38$ & $\leftarrow 2.28$ & $\leftarrow 2.51$ & $\uparrow 2.8571$ \\
\hline Fisik & & $\leftarrow \leftarrow 2.14$ & $\leftarrow 1.24$ & \begin{tabular}{|l|l|}
$\uparrow$ & 1.3698 \\
\end{tabular} & \begin{tabular}{|l|l|}
$\uparrow$ & 1.3157 \\
\end{tabular} & \begin{tabular}{l|l}
$\uparrow$ & 3.59 \\
\end{tabular} \\
\hline Karakteris & & & \begin{tabular}{|l|l|}
$\uparrow$ & 1.3157 \\
\end{tabular} & \begin{tabular}{|l|l|}
$\uparrow$ & 1.2345 \\
\end{tabular} & \begin{tabular}{|l|l|}
$\uparrow$ & 1.2345 \\
\end{tabular} & \begin{tabular}{|l|l|}
$\uparrow$ & 2.99 \\
\end{tabular} \\
\hline Mekanisme & & & & $\begin{array}{l}\leftarrow 1.06 \\
\end{array}$ & $\leftarrow 1.06$ & \begin{tabular}{l|l}
$\uparrow$ & 3.76 \\
\end{tabular} \\
\hline Prasarana & & & & & $\leftarrow 1.6129$ & $\uparrow 3.98$ \\
\hline Sarana & & & & & & \begin{tabular}{|l|l|}
$\uparrow 3.98$ \\
\end{tabular} \\
\hline
\end{tabular}

Gambar 3. Pemasukkan Nilai Gabungan dengan Model Matrix dalam Super Decisions.

Pada pemerintah dilakukan wawancara dan kuesioner ANP pada 6 sampel representatif yang berasal dari instansi pemerintahan yang berkaitan dengan pembangunan apartemen yaitu BAPPEKO/BAPPEDA dan Dinas Pekerjaan Umum Cipta Karya dan Tata Ruang. Dari hasil analisis ANP didapatkan nilai bobot faktor dan sub faktor prioritas pemilihan lokasi apartemen menurut sudut pandang pemerintah yaitu sebagai berikut:

Tabel 3

Prioritas Faktor Pemilihan Lokasi Apartemen Berdasarkan Preferensi Pemerintah

\begin{tabular}{lcc}
\hline \hline \multicolumn{1}{c}{ Faktor } & Limitting & Peringkat \\
\hline Aksesibilitas & 0,2101 & 2 \\
Fisik & 0,0886 & 5 \\
Karakteristik Lingkungan & 0,0692 & 7 \\
Mekanisme Pasar & 0,0963 & 4 \\
Sarana & 0,0982 & 3 \\
Prasarana & 0,0841 & 6 \\
Tata Ruang & 0,3535 & 1 \\
\hline \hline
\end{tabular}

Dapat diketahui bahwa faktor prioritas dalam pemilihan lokasi apartemen menurut preferensi pemerintah adalah tata ruang dengan bobot 0,3535 ; aksesibilitas dengan bobot 0,2101 ; sarana dengan bobot 0,0982; mekanisme pasar dengan bobot 0,0963; fisik dengan bobot 0,0886 ; prasarana dengan bobot 0,0841; dan karakteristik lingkungan dengan bobot 0,0692 .

Tabel 4

Prioritas Sub Faktor Pemilihan Lokasi Apartemen Berdasarkan Preferensi Pemerintah

\begin{tabular}{lcc}
\hline \hline \multicolumn{1}{c}{ Sub Faktor } & $\begin{array}{c}\text { Normalized } \\
\text { Cluster }\end{array}$ & Limitting \\
\hline Kesesuaian dengan RTRW & 0,6586 & 0,2326 \\
Harga lahan & 0,3414 & 0,1205 \\
Jarak ke jalan utama & 0,5723 & 0,1156 \\
Jarak ke pusat pelayanan & 0,3039 & 0,0614 \\
kota & & \\
Tingkat keamanan & 0,7407 & 0,0473 \\
Genangan pada lahan & 0,5291 & 0,0433 \\
Permintaan pasar & 0,4795 & 0,0425 \\
Topografi & 0,4709 & 0,0385 \\
Pendidikan & 0,3012 & 0,0362 \\
Kemampuan pengembang & 0,3971 & 0,0352 \\
Kesehatan & 0,2550 & 0,0306 \\
Rekreasi & 0,2223 & 0,0267 \\
RTH & 0,2215 & 0,0266 \\
Ketersediaan angkutan & 0,1239 & 0,0250 \\
umum & 0,2165 & 0,0196 \\
Jaringan air bersih & 0,2095 & 0,0190 \\
Jaringan listrik & 0,2003 & 0,0181 \\
Jaringan telepon & 0,1922 & 0,0174 \\
Jaringan drainase & 0,2593 & 0,0166 \\
Estetika & 0,1816 & 0,0164 \\
Jaringan jalan & 0,1233 & 0,0109 \\
Proyeksi penduduk & & \\
\hline \hline Dari hasil & & \\
\hline
\end{tabular}

Dari hasil pembobotan di atas bahwa sub faktor yang diprioritaskan oleh pemerintah ialah kesesuaian lokasi apartemen dengan dokumen RTRW dengan bobot 0,2326 atau $23 \%$. Kemudian sub faktor harga lahan, jarak ke jalan utama, dan jarak ke pusat pelayanan kota memiliki nilai bobot yang tinggi setelah kesesuaian dengan RTRW dibandingkan dengan sub faktor lainnya. Menurut pemerintah, sub faktor lainnya pada faktor fisik, karakteristik lingkungan, sarana, dan prasarana mengikuti arahan rencana tata ruang yang ada. 


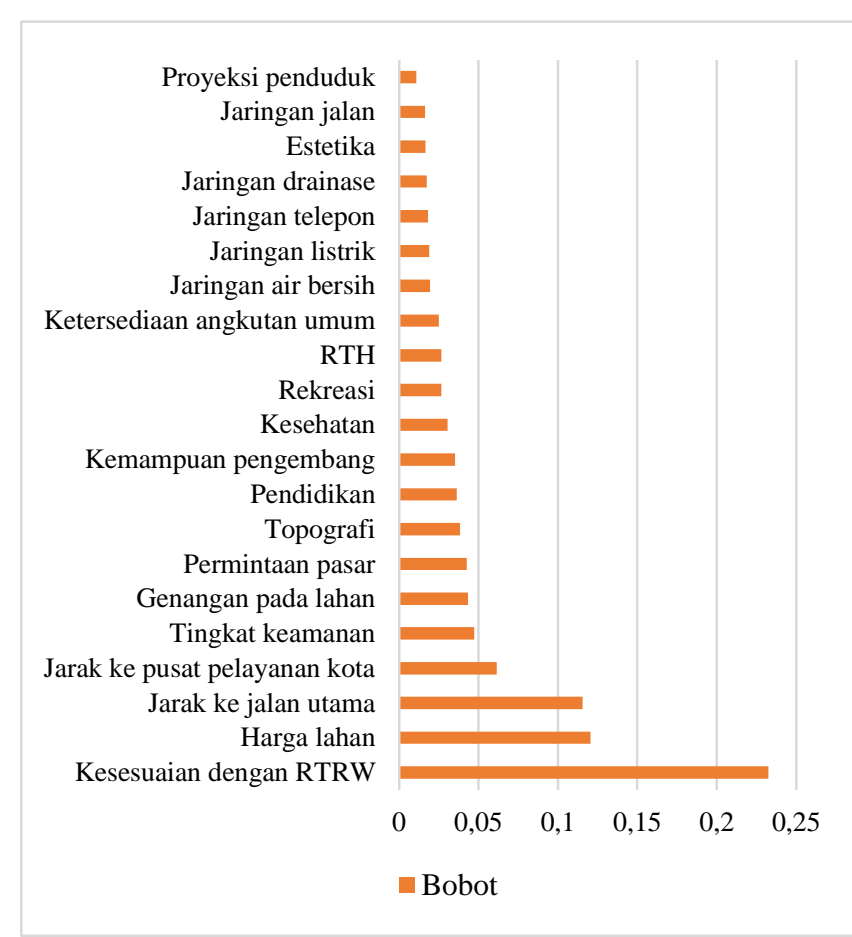

Gambar 2. Diagram Pembobotan Prioritas Sub Faktor Pemilihan Lokasi Apartemen Berdasarkan Preferensi Pemerintah.

Kesesuaian dengan RTRW merupakan sub faktor yang diprioritaskan pertama oleh pemerintah. Kesesuaian dengan RTRW merupakan faktor penting dalam pertimbangan perencanaan apartemen [11]. Peran pemerintah sebagai pengatur penentuan lokasi bangunan tinggi dalam regulasi dan pemberi perijinan pembangunan apartemen sehingga dalam pemilihan lokasi apartemen pihak pemerintah lebih memprioritaskan pembangunan apartemen yang sesuai dengan arahan rencana yang ada. RTRW berfungsi sebagai arahan perizinan lokasi apartemen yang didetailkan kembali ke dalam Rencana Detail Tata Ruang dan Peraturan Zonasi. RDTR dan PZ memuat arahan rencana berdasarkan Unit Pengembangan yang memuat perencanaan presentase koefisien lantai bangunan, koefisien dasar bangunan, dsb. Selain itu, lokasi apartemen diizinkan berada di zona permukiman dan zona perdagangan dan jasa. Hal ini disebabkan bangunan apartemen merupakan bangunan dengan penggunaan lahan campuran. Rencana-rencana tersebut juga berfungsi untuk mengetahui apakah pembangunan dan pemilihan lokasi apartemen telah sesuai dengan peruntukkan zona.

Selain rencana, adapun proses perizinan berupa AMDAL, IMB, dan sebagainya untuk mengetahui rencana kota pada lokasi yang dimohonkan seperti peruntukkan GSB, GSJ, KDB, KLB, dll. Proses tersebut wajib dilakukan agar dapat mengetahui pebangunan telah sesuai dengan arahan rencana dan menentukan bentuk peningkatan atau perbaikan yang perlu dilakukan untuk mengakomodasi perubahan yang terjadi akibat pembangunan baru. Hal tersebut juga berlaku pada pengendalian lokasi apartemen di Kabupaten Sidoarjo dan Kabupaten Gresik. Pemerintah Kabupaten Gresik mengarahkan agar lokasi apartemen berada di kawasan perkotaan Gresik yaitu Kecamatan Gresik dan sebagian Kecamatan Kebomas. Pemerintah Gresik mengharapkan dengan adanya apartemen yang berfungsi sebagai tempat tinggal yang dihuni oleh masyarakat dapat mampu mengurangi adanya kebutuhan akan tempat tinggal.

Harga lahan merupakan sub faktor kedua yang diprioritaskan dengan bobot nilai sebesar 0,1205 atau $12 \%$. Besarnya harga lahan dapat menggambarkan kestrategisan lokasi apartemen yang dimiliki oleh pengembang. Lahan yang memiliki kedekatan dengan jalan utama dan pusat pelayanan kota memiliki harga lahan yang lebih tinggi dibandingkan yang berada di pinggiran kota. Dalam Kajian Zonasi Bangunan Bertingkat Tinggi di Kota Surabaya, terdapat beberapa faktor yang menentukan dalam pengembangan kawasan bangunan bertingkat tinggi yaitu peraturan dan rencana tata ruang, ketersediaan lahan, kawasan keselamatan operasi penerbangan (KKOP), harga lahan, dan bangkitan dan tarikan lalu lintas [12]. Hal tersebut juga didukung oleh teori Von Thunen yang mengatakan bahwa semakin jauh lokasi lahan terhadap pusat kota maka akan semakin rendah tingkat harga lahannya. Begitu pula sebaliknya, semakin mendekati pusat perkotaan maka harga lahan akan semakin tinggi. Pemerintah menganggap bahwa memilih lokasi dengan harga lahan yang tinggi dipercaya bahwa lokasi tersebut memiliki kedekatan dengan fasilitas perkotaan yang lengkap seperti kemudahan akses, ketersediaan sarana dan prasarana, dll.

Keberadaan jarak ke jalan utama merupakan faktor yang dipertimbangkan oleh pemerintah dalam perizinan lokasi apartemen dengan bobot nilai sebesar 0,1156 atau $12 \%$. Apartemen dengan penggunaan lahan campuran pada umumnya didirikan di pusat-pusat perkotaan, sepanjang jalan utama, ataupun dekat dengan jaringan transportasi umum [13]. Hal tersebut berhubungan dengan kemudahan akses keluar masuk apartemen menuju maupun ke luar apartemen. Wilayah pusat pelayanan kota merupakan pusat kegiatan Kota Surabaya yang memiliki kelengkapan kegiatan mulai dari perdagangan dan jasa, pendidikan, perkantoran, dll. Sesuai dengan arahan rencana UP VI Tunjungan, UP II Kertajaya, dan UP VIII Dukuh Pakis bahwa kegiatan yang berkembang di ketiga UP tersebut mengikuti pola jaringan jalan. Namun, terdapat hal yang membedakan wilayah pusat pelayanan kota dengan wilayah peralihan dan pinggiran yaitu rencana arahan pengembangan apartemen yang dimana memiliki kecenderungan hunian vertikal di wilayah peralihan berada pada koridor-koridor jalan utama salah satunya seperti Jalan Ahmad Yani. Jalan Ahmad Yani merupakan akses utama Kota Surabaya yang didominasi oleh kegiatan perdagangan dan jasa dan perkantoran skala regional. Namun begitu, terdapat beberapa apartemen yang tidak berada dekat dengan jalan utama seperti halnya pada Apartemen Menara Rungkut yang berada di Jalan Abdul Karim. Kemudian Apartemen Gunawangsa Gresik dan Icon Mall Apartment yang berada di Kabupaten Gresik terletak di jalan nasional. Pemerintah mengharapkan bahwa pengembang dapat memanfaatkan fasilitas kota yang ada seperti akses jalan nasional yang terhubung langsung dengan jalan tol menuju Kota Surabaya.

Berdasarkan hasil dari ANP, sub faktor jarak ke pusat pelayanan kota memiliki bobot nilai sebesar 0,03039 atau sebesar $30 \%$. Sub faktor tersebut menjadi salah satu sub faktor yang diprioritaskan karena sesuai dengan rencana arahan 
apartemen berdasarkan RDTR Kota Surabaya dimana apartemen diarahkan untuk dibangun di pusat pelayanan kota. Letak pusat pelayanan kota yang telah ditetapkan pada Peraturan Daerah Nomor 12 Tahun 2014 tentang RTRW Kota Surabaya ialah Kecamatan Genteng (UP VI Tunjungan), Kecamatan Mulyorejo (UP II Kertajaya), dan Kecamatan Sukomanunggal (UP VIII Dukuh Pakis). Sesuai dengan teori perencanaan high-rise building dimana apartemen merupakan salah satu bangunan bertingkat tinggi bahwa di dalam pemilihan lokasi perlu mempertimbangkan kedekatan dengan pusat kota. Kemudian di dalam teori compact city, pembangunan partemen diharapkan berkonsentrasi di dalam satu wilayah agar dapat mendorong efisiensi penggunaan lahan yang ramah lingkungan. Hal ini mengindikasikan bahwa persepsi pemerintah telah sesuai dengan teori-teori terdahulu. Namun di dalam kondisi eksisting saat ini apartemen banyak dibangun di wilayah pinggiran seperti Metropolis Apartment, Apartemen UC, Dian Regency Apartment, dsb. Kemunculan apartemen tersebut diakibatkan ingin mendekati lokasi pendidikan seperti Institut Teknologi Sepuluh Nopember, Universitas Airlangga, dll. Pembangunan apartemen saat ini cenderung ke arah mixed use. Selain itu, struktur Kota Surabaya telah menjadi multiple-nuclei yaitu struktur kota yang memiliki titik-titik yang bertindak sebagai pusat kegiatan seperti pusat bisnis, permukiman, industri, dll.

Kabupaten Sidoarjo dan Kabupaten Gresik yang merupakan wilayah pinggiran Kota Surabaya saat ini mulai dibangun apartemen dengan konsep mixed use. Menurut Pemerintah Kabupaten Gresik, lokasi pembangunan apartemen diarahkan di perkotaan Gresik dimana memanfaatkan akses, sarana, dan fasilitas yang ada. Akses yang digunakan di Kabupaten Gresik ialah jalan nasional yang menghubungkan Kabupaten Gresik dengan Kota Surabaya melalui jalan tol. Diharapkan lokasi tersebut dapat memudahkan pergerakan penghuni apartemen terutama pekerja ulang-alik. Sedangkan pengembangan hunian vertikal di Kabupaten Sidoarjo diarahkan di Kecamatan Waru dan Kecamatan Taman. Kecamatan tersebut merupakan wilayah yang berbatasan langsung dengan Kota Surabaya dimana memanfaatkan arahan rencana jalan non-tol yang direncanakan akan terhubungkan dengan MERR-II. Selain itu, kedekatan apartemen dengan fasilitas pendidikan merupakan salah satu faktor yang diprioritaskan oleh pemerintah di wilayah pinggiran. Hal ini disebabkan Kabupaten Sidoarjo dan Kabupaten Gresik yang masih memanfaatkan sarana pendidikan yang ada di Kota Surabaya seperti Institut Teknologi Sepuluh Nopember, Universitas Airlangga, dll.

\section{KESIMPULAN}

Apartemen yang merupakan salah satu solusi dari pemerintah untuk memenuhi kebutuhan tempat tinggal. Namun, kebijakan tersebut tidak diikuti oleh regulasi spesifik mengenai lokasi pembangunan apartemen sehingga lokasi apartemen di Kota Surabaya tidak merata. Hal tersebut menyebabkan wilayah sekitarnya mulai untuk membangun apartemen. Berdasarkan hasil analisis dan pembahasan yang telah dilakukan dalam penelitian ini, didapatkan hasil dari analisis Analytical Network Process bahwa faktor prioritas dalam pemilihan lokasi apartemen menurut preferensi pemerintah adalah kesesuaian dengan RTRW, harga lahan, jarak ke jalan utama, dan jarak ke pusat pelayanan kota.

\section{DAFTAR PUSTAKA}

[1] Pasal 6 Peraturan Daerah Kota Surabaya No 12 Tahun 2014. .

[2] F. Salanto, Surabaya Apartment Market Report. Colliers International Indonesia, 2015.

[3] S. Knox, P., \& Pinch, Urban Social Geography: An Introduction 6th Edition. Inggris: Pearson Education Limited, 2010.

[4] Retrieved March 2016, from Koran Sindo. 2016.

[5] "Rencana Tata Ruang Wilayah Kota Surabaya 2014-2034."

[6] Y. Triyandani, "Pengaruh Keberadaan Apartemen Terhadap Kinerja Jalan Arief Rahman Hakim Surabaya," J. Tek. POMITS, vol. 3, pp. C202-C206, 2014.

[7] M. E. Prakoso, "Manajemen Lalu Lintas Akibat Pembangunan Apartemen De Papilio Tamansari Surabaya," 2014.

[8] P. G. Aulia, B. U., Rahmawati, D., \& Ariastita, Land Suitability for High Rise Building Based on Land Developers' Preference and Soil Vulnerability Index. Procedia Social and Behavioral Sciences, 2014.

[9] A. N. Himawan, "Konsep Pembangunan Apartemen di Kota Surabaya (Preferensi Konsumen dan Developer)," 2016.

[10] I. A. Sandy, "Penerapan Metode Analytical Network Process (ANP) Untuk Pemilihan Supplier Bahan Baku Pada CV TX," in Seminar Nasional IENACO, 2013, pp. 1-7.

[11] A. Farouk, High Rise Buildings and How They Affect Countries Progression. Egypt, 2011.

[12] Badan Perencanaan Pembangunan Kota, Laporan Akhir Kajian Zonasi Bangunan Bertingkat Tinggi di Kota Surabaya. Surabaya, 2013.

[13] Auckland Council, "Guidance for Apartments," 2016. [Online]. Available: http://www.aucklanddesignmanual.co.nz/projecttype/buildings-and-sites/housing/apartments/guidance/thebuilding/Apartment-building-types/apartment-building-types-basicforms\#/project-type/buildings-and-

sites/housing/apartments/guidance/the-building/Apartm. 